\title{
Effect of Seagrass Liquid Extracts on Bell Pepper (Capsicum annuum) Under Salt Stress Conditions.
}

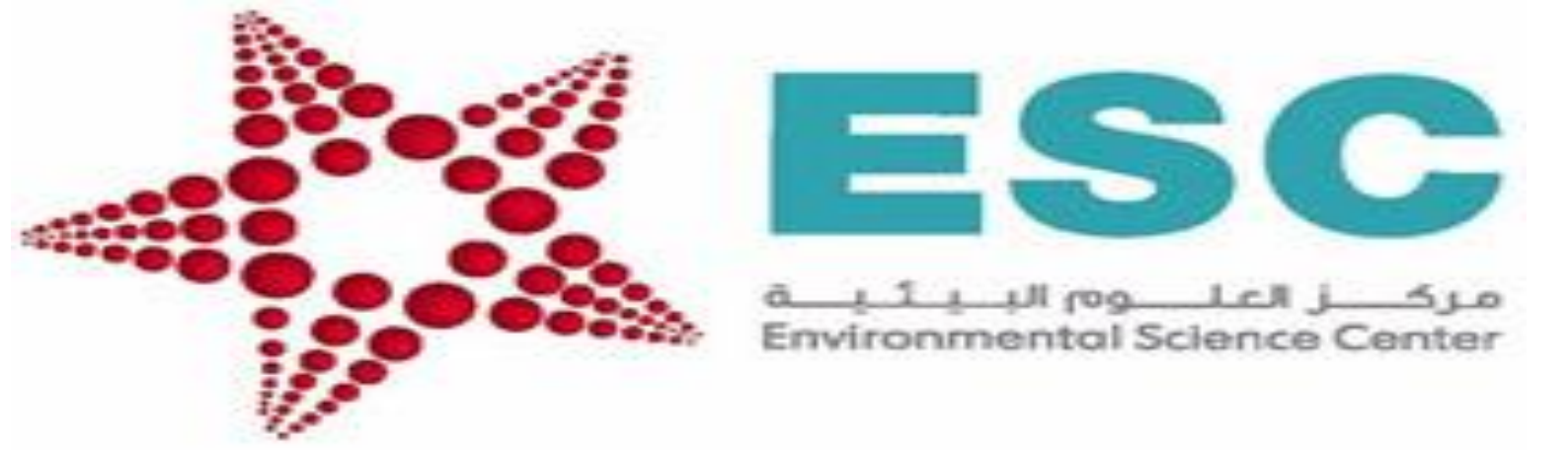

Undergraduate Students, Sciences and Engineering

\author{
Noora Al-qahtani ${ }^{1}$ and Talaat Ahmed ${ }^{2 *}$ \\ ${ }^{1}$ Department of Biological and Environmental Sciences, \\ College of Arts and Sciences, Qatar University \\ ${ }^{2}$ Environmental Science Center, Qatar University \\ "Corresponding author: t.alfattah@qu.edu.qa
}

كلية الآداب والعلوم College of Arts and Sciences

\section{Abstract}

Salinity is considered as a major environmental challenge that affect crop growth and productivity. This study investigated the application of Haodule univervis seagrass liquid extract on bell pepper (Capsicum annuит L.) under salt stress conditions. The salinity treatments were applied by irrigating bell pepper plants with $0,50,100,150$ and $200 \mathrm{mM} / \mathrm{l}$ of $\mathrm{NaCl}$ with four replications. The bell pepper plants were divided into two groups: one group was sprayed with seagrass extract, and the other group was sprayed with distilled water. The salt treatment was applied at every 10 days interval for only three treatments, and the bell pepper leaves were sprayed about seven days after the salt treatment. The results showed an increase in relative water content (RWC) of salt stressed bell pepper plants sprayed with seagrass extract from $0-100 \mathrm{mM}$ of $\mathrm{NaCl}$ treatment, while RWC decreased at 150 and $200 \mathrm{mM} \mathrm{NaCl}$ treatments compared to the control. This indicates stressed bell pepper plants sprayed with seagrass extract had higher RWC than plants sprayed with water at $0-100 \mathrm{mM} \mathrm{NaCl}$ treatments. Chlorophyll concentration was decreased dramatically in plants sprayed with water at $50 \mathrm{mM}$ of $\mathrm{NaCl}$ level. However, chlorophyll concentration increased slightly in plants sprayed with water at $100 \mathrm{mM} \mathrm{NaCl}$ level then start declined gradually at $150 \mathrm{mM}$ and $200 \mathrm{mM} \mathrm{NaCl}$ level. The plants sprayed with seagrass extract shown increase in chlorophyll concentration at 100 and $150 \mathrm{mM} \mathrm{NaCl}$ treatment compared to the control. Fresh weights of plants sprayed with seagrass extract were declined at 50-150 mM $\mathrm{NaCl}$ compared to the control. However, the highest dry weights of plants sprayed with seagrass at $100 \mathrm{mM} \mathrm{NaCl}$ treatment. In addition, plants sprayed with water does not show variations in fresh and dry weights.

\section{Introduction}

Bell pepper (Capsicum annuиm L.) is widely consumed as high source of vitamin $\mathrm{C}$ and health enhancing effects. There are many bell pepper cultivars that produce fruits in different colors, including red, yellow, orange, green, white, and purple. There are many studies were conducted to group different available bell pepper (Capsicum annиum L.) germplasms into salt tolerant, moderately tolerant and sensitive ones based on seed germination and morphological and yield characteristics. Bell pepper is considered one of the most vegetable common crops that are grown under greenhouse. It is classified as moderately sensitive to salinity (Ayers and Westcot, 1985) Many severe problems such as a reduction in fruit size (Navarro et al., 2002) and an increase in the frequency of blossom-end rot (Rubio et al., 2009) could be occurred as a result of using high salinity irrigation water. Additionally, irrigation with saline water could lead to high decreases in growth, disturbances in membrane permeability, water channel activity, stomatal conductance, photosynthesis and ion balance (Bethke and Drew, 1992; Navarro et al., 2003; Cabanero et al..2004; Aktas et al., 2006).

The bioactive compounds extracted from the marine seagrass have been found to have a prompting activity when they are applied to the crop plant leaves. Seagrasses have been used as soil conditioners to increase the yield and productivity of the many crop plants as an eco-friendly way.

\section{Objective}

- Investigate the application of Haodule univervis seagrass extract as foliar spray on salt stress bell pepper plants (Capsicum аппиит L.) under salt stress conditions.
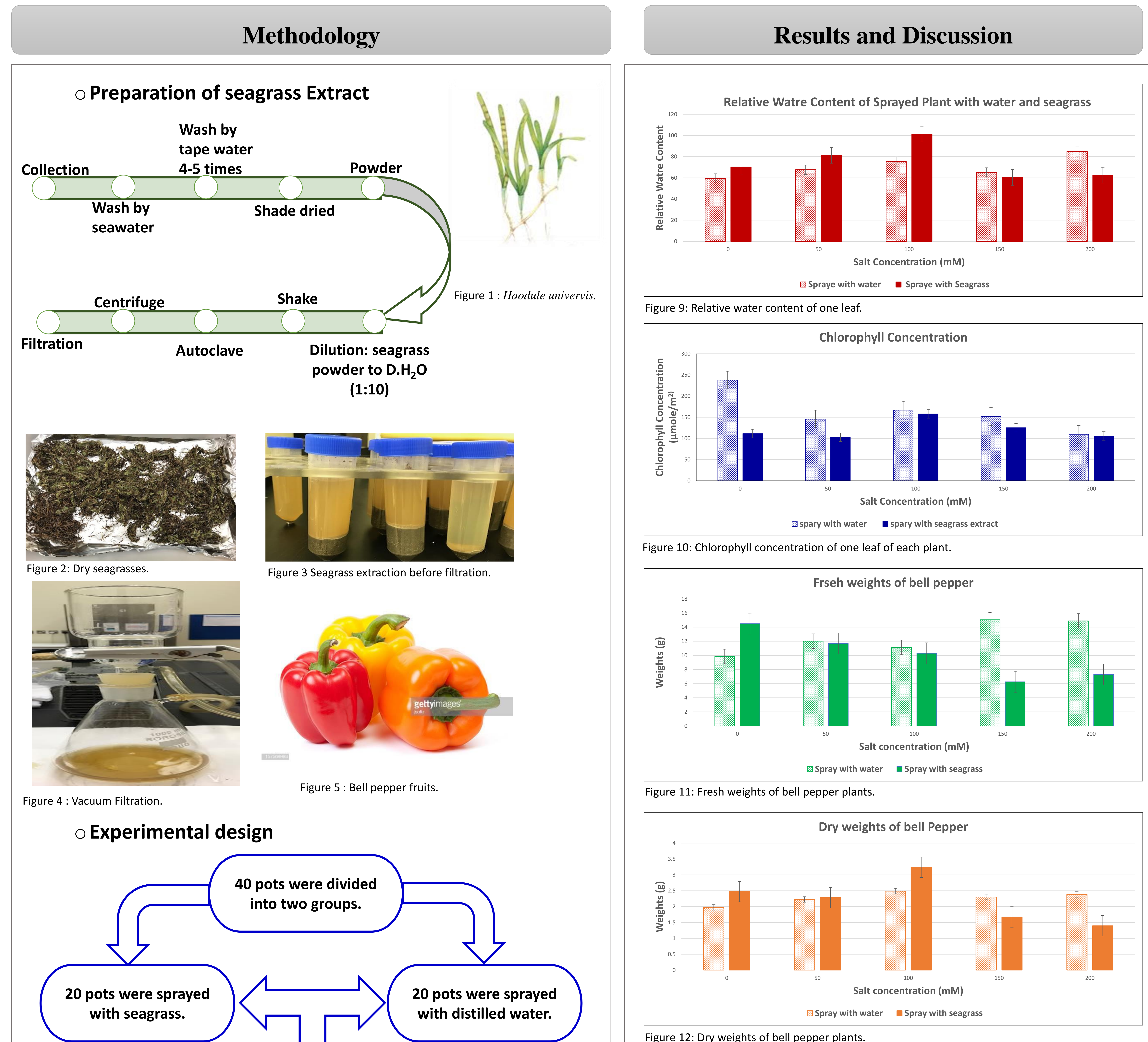

The results showed the relative water content of salt stressed plants sprayed with seagrass extract at $100 \mathrm{mM} \mathrm{NaCl}$ treatment had the highest (RWC) compared to the control, while plants sprayed with water showed an increase at 50 and $100 \mathrm{mM} \mathrm{NaCl}$ compared to the control (Figure 9). Furthermore, chlorophyll concentration of plants sprayed with seagrass increased at 100 and $150 \mathrm{mM} \mathrm{NaCl}$ compared to the control (Figure 10). Fresh weights of plants sprayed with seagrass extract were declined with increase salt stress from 0-150 $\mathrm{mM} \mathrm{NaCl}$ (Figure 11), while dry weights slight increase at 0 and $50 \mathrm{mM} \mathrm{NaCl}$ then it increased dramatically at 100 $\mathrm{mM} \mathrm{NaCl}$ (Figure 12). plants sprayed with water does not show variations in fresh and dry weights. Seagrass Extract had a protective mechanisms against salt stress ( Vinoth et al., 2017).

\section{Conclusion}

In conclusion, the application of Haodule univervis liquid extract can be used to enhance tolerance in bell pepper plants under salt stress conditions. Plants sprayed with seagrass extract showed positive results in relative water content, chlorophyll concentration, and fresh weights and dry weights.

\section{Acknowledgments}

This project was supported by Qatar University Internal Grant No. QUST-2-ESC-2019-1 achieved herein are solely the responsibility of the authors.

\section{References}

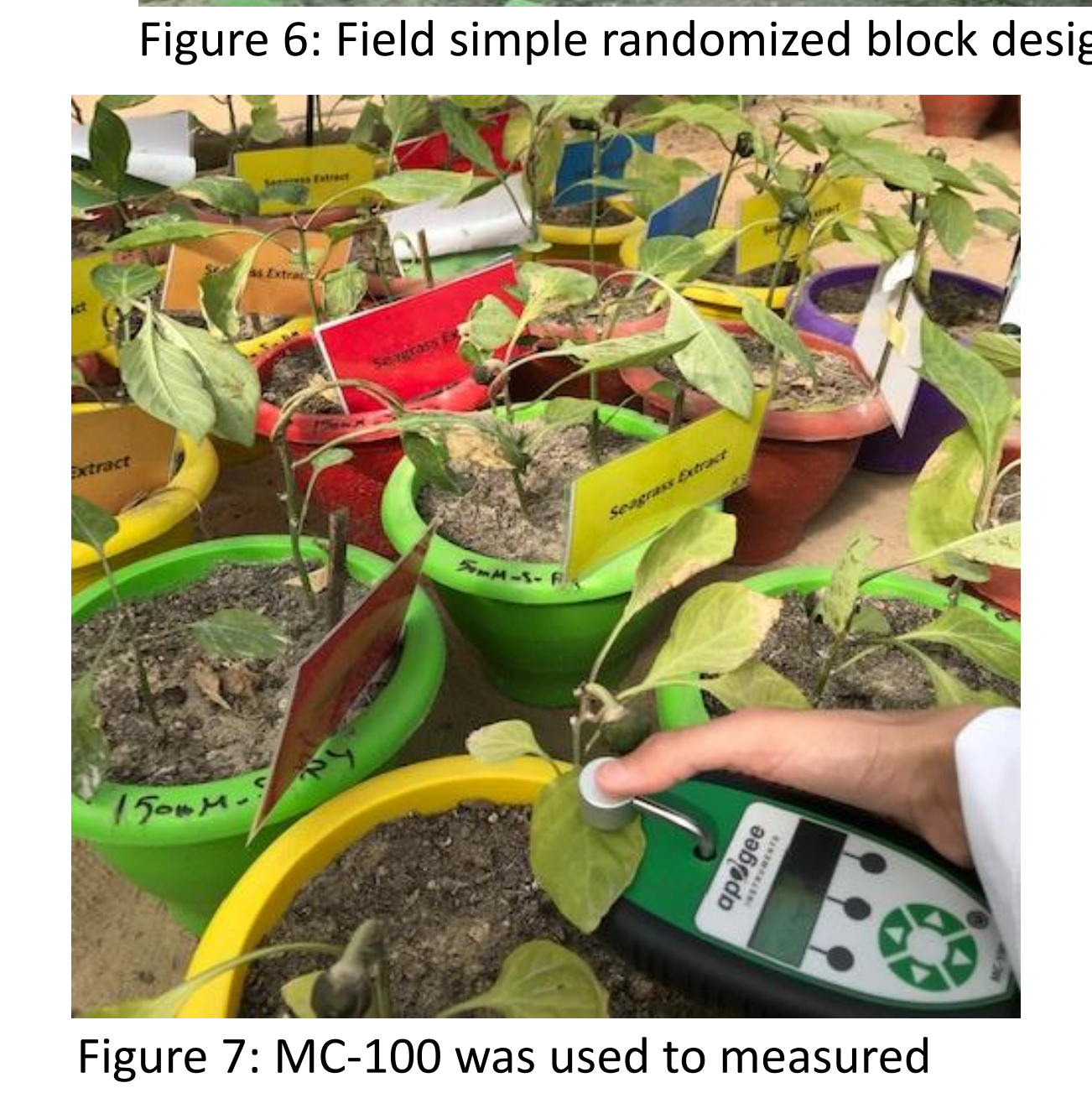
chlorophyll concentration .

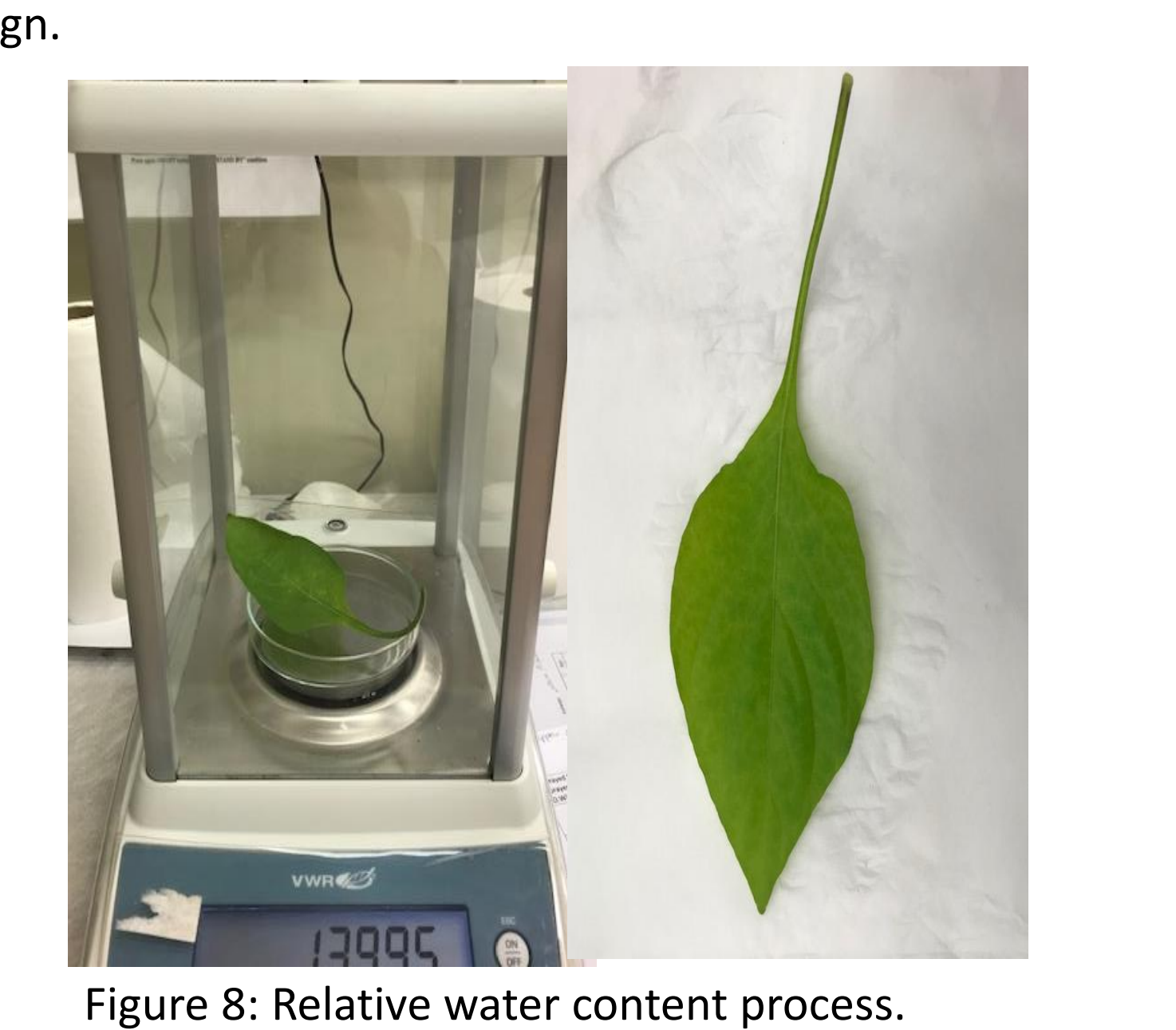

